Article

\title{
Evolution of Tembusu Virus in Ducks, Chickens, Geese, Sparrows, and Mosquitoes in Northern China
}

\author{
Guanliu Yu ${ }^{1,2,3}$, Yun Lin ${ }^{1,2,3}$, Yi Tang ${ }^{1,2,3, *}$ and Youxiang Diao ${ }^{1,2,3, *}$ \\ 1 College of Animal Science and Technology, Shandong Agricultural University, 61 Daizong Road, \\ Tai'an 271018, Shandong Province, China; yuguanliu@163.com (G.Y.); lyun1994@126.com (Y.L.) \\ 2 Shandong Provincial Key Laboratory of Animal Biotechnology and Disease Control and Prevention, \\ Shandong Agricultural University, 61 Daizong Road, Tai'an 271018, Shandong Province, China \\ 3 Shandong Provincial Engineering Technology Research Center of Animal Disease Control and Prevention, \\ Shandong Agricultural University, 61 Daizong Road, Tai'an 271018, Shandong Province, China \\ * Correspondence: tyck288@163.com (Y.T.); yxdiao@126.com (Y.D.)
}

Received: 22 August 2018; Accepted: 6 September 2018; Published: 10 September 2018

check for updates

\begin{abstract}
Tembusu virus (TMUV) is a contagious pathogen from fowl that mainly infects ducks and geese, causing symptoms of high fever, loss of appetite, retarded growth, neurological symptoms, severe duck-drop syndrome, and even death. During an epidemiological investigation of TMUV in Northern China, we isolated 11 TMUV strains from ducks, chickens, geese, sparrows, and mosquitoes (2011-2017). Phylogenetic analysis of the open-reading frames of genes revealed that these strains clustered into Chinese strains II. The nucleotide and amino acid homologies of NS1 of the strains ranged between $85.8-99.8 \%$ and $92.5-99.68 \%$, respectively, which were lower than those of $E$ (86.7-99.9\% and 96.5-99.9\%, respectively), NS3 (87.6-99.9\% and 98.2-99.8\%, respectively), and NS5 (86.5-99.9\% and 97.8-99.9\%, respectively). Predictions of the tertiary structure of the viral proteins indicated that NS1 in 4 of 11 strains had a protein structure mutation at ${ }^{180} \mathrm{TAV}^{182}$ that changed a random crimp into an alpha helix. The protein of 6 of 11 strains had a glycosylation site mutation from NTTD to NITD. Furthermore, epidemiological data suggested that TMUV has been circulating in half of China's provinces (17 of 34). Our findings, for the first time, have identified the NS1 protein as a potential hypervariable region for genetic evolution. Additionally, the territorial scope of the virus has expanded, requiring strict bio-security measures or a multivalent vaccine to control its spread.
\end{abstract}

Keywords: Tembusu virus; phylogenetic analysis; duck; protein structure; glycosylation

\section{Introduction}

Duck, as a major fowl species in China, offers high-economic benefits with a population of up to 20-30 billion per year [1]. Unfortunately, hemorrhagic ovarian inflammation, which is also named egg-drop syndrome and is mainly caused by Tembusu virus (TMUV), has resulted in large economic losses of several billion dollars for the Chinese duck-rearing industry since April 2010 [2].

TMUV, similar to other flaviviruses, has an approximately 11-kb positive-sense single-stranded RNA genome composed of one long open-reading frame (ORF) encoding three structural proteins, namely capsid, membrane precursor (which is post-translationally cleaved to produce pr and $\mathrm{M}$ proteins), and envelope, followed by seven non-structural proteins (NS1, NS2A, NS2B, NS3, NS4A, NS4B, and NS5) [2]. The virus was first isolated from Culex tritaeniorhynchus in Malaysia in 1955 [3], after which there were no reports regarding viral outbreaks for more than half a century, excluding a chick-origin TMUV (also named Sitiawan virus) isolated in Malaysia in 2000 [4]. In recent years, after initial outbreaks in Shanghai in April 2010, no major epidemics of duck TMUV (DTMUV) infection were observed throughout 2011, and the disease occurred only sporadically in some 
individual farms [5]. Nevertheless, the viral infectious disease occurred again in ducks in the major duck-producing region of mainland China in 2012. The cause of these irregular outbreaks demands attention.

As a novel member of Flavivirus, this virus has devastating effects on ducks, and can infect geese [6-8], chickens [9], mosquitoes [10], sparrows [11], pigeons [12], and mice [13,14]. Furthermore, the virus antibodies have been detected in the serum of 132 duck industry workers, and the serum positive rate was $71.9 \%$ (95 of 132) [15]. These findings indicate that the virus has expanded its host range, suggesting it may pose a threat to public health.

Therefore, to better understand the genetic divergence of TMUV in Northern China and provide a foundation for establishing strategies to control TMUV spread, genetic evolution analysis methods (i.e., phylogenetic analysis, predictions of protein tertiary structures and glycosylation sites) were employed to explore the genetic divergence of 11 TMUV strains isolated from ducks, chickens, geese, sparrows, and mosquitoes in Northern China between 2011 and 2017. Furthermore, to objectively reflect TMUV prevalence in China at present, an epidemiological survey of TMUV infection in 17 provinces of China between 2014 and 2017 was also conducted.

\section{Materials and Methods}

\subsection{Ethics Statement}

This study was approved by the Animal Care and Use Committee of Shandong Agricultural University (permit number: 2018061, April, 2018) and performed in accordance with the guidelines of the committee on ethics of experimental animals of Shandong, China.

\subsection{Epidemiological Survey}

In this study, 308 clinical samples (i.e., brains, livers and ovaries of ducks, geese, and chickens) with suspected TMUV infection were collected from 17 provinces between 2014 and 2017. The samples were stored at $-80{ }^{\circ} \mathrm{C}$ prior to RNA extraction. Total RNA was extracted, treated, tested for quality, stored, and reverse-transcribed to cDNA as described in our previous study [11]. DTMUV-positive samples were examined via reverse transcription-polymerase chain reaction (RT-PCR) using specific primers (Table S2). The PCR program was set as follows: $94{ }^{\circ} \mathrm{C}$ for $5 \mathrm{~min}$ for the initial denaturation; 33 cycles of denaturation at $94{ }^{\circ} \mathrm{C}$ for $45 \mathrm{~s}$, annealing at $57^{\circ} \mathrm{C}$ for $55 \mathrm{~s}$, and extension at $72{ }^{\circ} \mathrm{C}$ for $50 \mathrm{~s}$; and a final extension at $72{ }^{\circ} \mathrm{C}$ for $8 \mathrm{~min}$. The PCR products were purified and cloned into the pMD18-T vector (TaKaRa, Dalian, China), and sequenced using the Sanger sequencing assay (TsingKe Biotech, Beijing, China). Positive results were confirmed by comparing the sequences to reference sequences.

\subsection{Virus Isolate Descriptions}

Over the past 8 years, our team isolated 11 TMUV strains from TMUV-infected ducks, chickens, geese, sparrows, and mosquitoes. As for the virus isolation of ducks, geese, sparrows, and chickens, the liver or brain samples were collected and homogenized in sterile phosphate-buffered saline (PBS, $\mathrm{pH} 7.2)$ containing antibiotics $(20 \% \mathrm{w} / \mathrm{v})$. After centrifugation at $6000 \mathrm{~g}$ for $30 \mathrm{~min}$, the supernatants were filtered through a $0.2 \mu \mathrm{m}$ syringe-driven filter (Thermo Scientific, Lenexa, KS, USA). The filtered suspension was then inoculated into 9-day-old SPF duck embryos through the allantoic cavity route [11]. The amnioallantoic fluids of the infected embryos were collected for further passage and RNA extraction. The RNA extraction was carried out with an RNA extraction kit (TIANGEN, Beijing, China), following the manufacturer's instructions.

With regard to the virus isolation from mosquitoes near to duck farms with TMUV infection outbreaks, the collected mosquitoes were sorted, based on species, with a maximum of 25 adult mosquitoes per pool and stored at $-80^{\circ} \mathrm{C}$ in $1.5 \mathrm{~mL}$ centrifuge tubes [10]. The detection and isolation of mosquito-origin TMUV was the same to that of the above birds-origin TMUV. Nucleotide acid 
samples of these isolates were sequenced using Sanger sequencing. Detailed information about these isolates is provided in Table 1.

Table 1. Summary of the 11 Tembusu virus isolates obtained from the northern provinces of China (2011-2017).

\begin{tabular}{cccccccc}
\hline Strains & Host & Age & Tissue & Co-Infection & Location & Date & Accession \\
\hline TC2B & Layer duck & $16 \mathrm{~d}$ & Liver & - & SD & 2011.09 .25 & MH764605 \\
SDSG & Layer duck & $30 \mathrm{~d}$ & Liver & H9 & SD & 2011.11 .01 & KJ740746 \\
lq-1 & Goose & $58 \mathrm{~d}$ & Brain & GoCV, GPV & SD & 2012.10 .26 & KF557893 \\
SDMS & Culex mosquito & - & Body & - & SD & 2012.06 .01 & KC333867 [10] \\
SDHS & House sparrow & - & Liver & - & SD & 2012.12 .15 & KF826767 [11] \\
SX1 & Layer chicken & $45 \mathrm{~d}$ & Liver & H9 & SD & 2013.11 .22 & KM066945 \\
SDXT & Layer duck & $210 \mathrm{~d}$ & Liver & DHAV-1 & SD & 2013.10 .01 & KJ740745 \\
SDLC & Layer duck & $103 \mathrm{~d}$ & Liver & H7, H9 & SD & 2013.11 .01 & KJ740747 \\
AHQY & Layer duck & $160 \mathrm{~d}$ & Liver & - & AH & 2013.11 .06 & KJ740748 \\
SDDZ & Meat duck & $36 \mathrm{~d}$ & Liver & FAdV-4 & SD & 2016.10 .17 & MH764606 \\
NMCF & Meat duck & $22 \mathrm{~d}$ & Liver & DHAV-1 & IM & 2017.01 .02 & MH764607 \\
\hline
\end{tabular}

Note, SD: Shandong; AH: Anhui; IM: Inner Mongolia; GoCV: Goose circovirus; GPV: Goose parvovirus; DHAV-1: Duck hepatitis A virus type 1; H7: H7 subtype influenza virus; H9: H9 subtype influenza virus; FAdV-4: Fowl adenovirus serotype 4 .

\subsection{Phylogenetic Analysis}

To determine the genetic divergence of the 11 TMUV isolates, 78 TMUV representative ORF sequences were extracted from GenBank. These sequences represented six host species, including 63 ducks, 6 geese, 5 chickens, 2 mosquitoes, 1 sparrow, and 1 pigeon. Detailed information about these strains is listed in Supplementary Table S1.

The phylogenetic trees of the 78 TMUV ORF sequences were constructed via the neighbor-joining method using MEGA software (version 7.0.20, Tempe, AZ, USA) with 1000 bootstrap replicates. Furthermore, the nucleotide and amino acid homologies of the 11 isolates and 67 other representative strains were analyzed using the ClustalW multiple alignment function of BioEdit (version 7.0.5.2, Ibis Biosciences, Carlsbad, CA, USA).

\subsection{Viral Protein Structure Modeling and Glycosylation Site Prediction}

To visually reflect the mutations of the 11 TMUV isolates, the tertiary structures of E, NS1, NS3, and NS5 of these isolates were modeled using Swiss Model (https:/ / swissmodel.expasy.org/ interactive). The model templates of E, NS1, NS3, and NS5 proteins were 5wsn.1.A, 5gs6.1A, 2wv9.1, and $4 \mathrm{k} 6 \mathrm{~m} .1$, respectively.

The N-glycosylation sites of the four aforementioned proteins were predicted using Glycam (http://glycam.ccrc.uga.edu), which identifies potential N-glycosylation sites by calculating the solvent accessible surface area of Asn in Asn-XThr/Ser/Cys motifs (X represents any amino acid).

\section{Results}

\subsection{Epidemiological Survey}

From 2014 to 2017, 308 clinical samples with suspected TMUV infection were collected in 17 Chinese provinces by our team, and 212 positive samples were identified by RT-PCR and sequence analysis. The TMUV-positive sample spatial distribution information is shown in Figure 1. TMUV has been circulating in half of the provinces of China (17 of 34) (Figure 1a,c). Notably, the incidence in autumn was higher than in spring, summer, and winter (i.e., 90 vs. 28, 50, and 44 respectively; Figure 1b). 


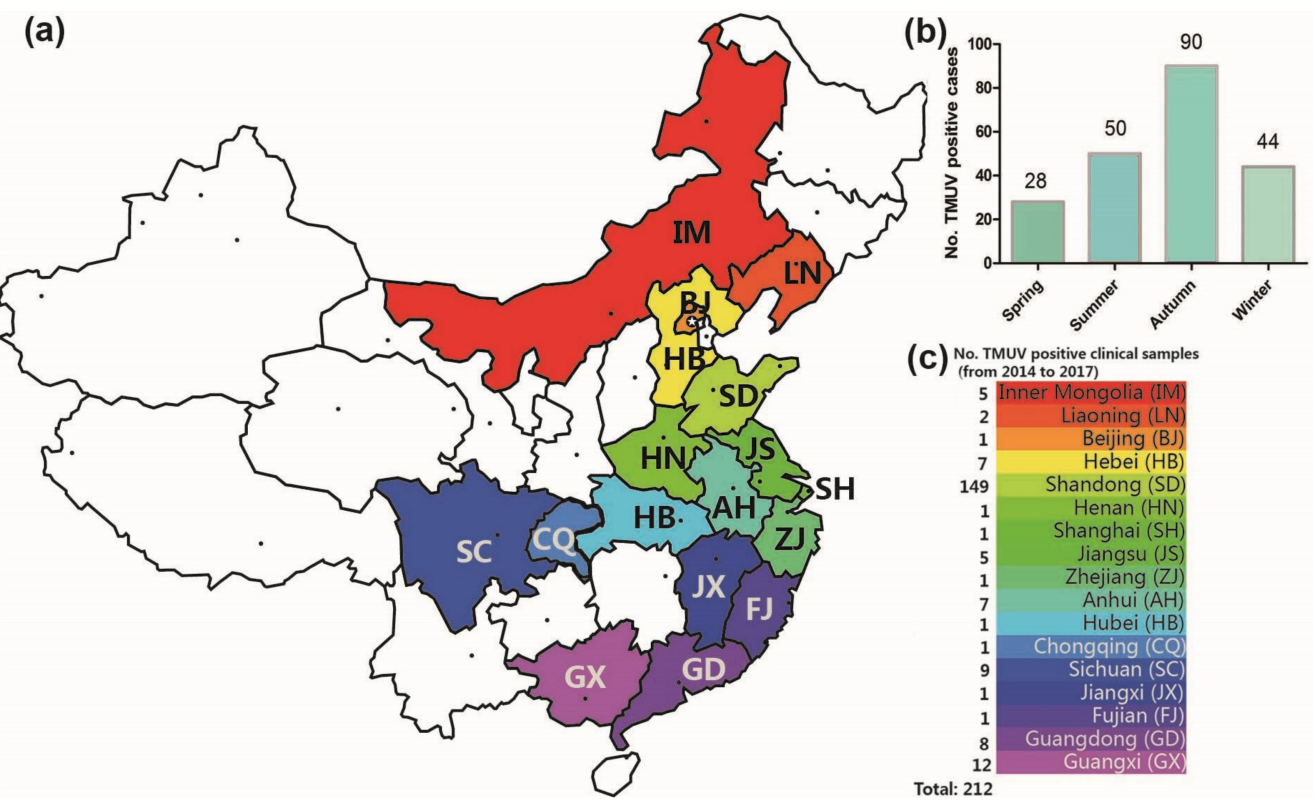

Figure 1. The geographical distribution of clinical samples (a). The number of TMUV positive cases in the four seasons (2014-2017) (b). In total, 212 Tembusu virus-positive samples were detected via reverse transcription-polymerase chain reaction in 17 Chinese provinces between 2014 and 2017 (c).

\subsection{Phylogenetic Analysis}

According to phylogenetic analysis of the ORF sequences of 78 representative TMUV strains in South Asia and China, these isolates mainly clustered into five major groups: Malaysia strains I, Malaysia strains II, Thailand strains, Chinese strains I, and Chinese strains II (Figure 2). The phylogenetic trees of the E, NS1, NS3, and NS5 sequences of the 78 representative strains were analogous to the ORF trees, as presented in Supplementary Figures S1-S4 respectively.

We isolated 11 strains of TMUV from Northern China between 2011 and 2017, and these isolates clustered into Chinese strains II (Figure 2).

Furthermore, based on the nucleotide and amino acid homology analysis of $E, N S 1, N S 3$, and NS5 of the 11 isolates and 67 other representative TMUV strains, the mean nucleotide and amino acid homologies of NS1 were lower than those of E, NS3, and NS5 (i.e., (85.8-99.8\% and $92.5-99.68 \%$ ) vs. (86.7-99.9\% and $96.5-99.9 \%),(87.6-99.9 \%$ and $98.2-99.8 \%)$, and (86.5-99.9\% and $97.8-99.9 \%)$ respectively) (Table 2), indicating that NS1 is more variable than the other proteins.

Table 2. Nucleotide and amino acid homologies of E, NS1, NS3, and NS5 of the 11 Tembusu virus isolates (compared with 67 reference strains).

\begin{tabular}{|c|c|c|c|c|c|c|c|c|}
\hline \multirow{2}{*}{ Strains } & \multicolumn{4}{|c|}{ Nucleotide Homology (nt, \%) } & \multicolumn{4}{|c|}{ Amino Acid Homology (aa, \%) } \\
\hline & $\mathbf{E}$ & NS1 & NS3 & NS5 & $\mathrm{E}$ & NS1 & NS3 & NS5 \\
\hline TC2B & $86.8-100.0$ & $86.2-100.0$ & $87.7-100.0$ & $86.5-100.0$ & 96.6-100.0 & $93.5-100.0$ & 98.4-100.0 & 97.9-100.0 \\
\hline lq-1 & 86.4-99.6 & $84.5-99.1$ & $87.5-100.0$ & 86.3-99.5 & $95.6-99.4$ & 88.4-98.3 & 98.1-100.0 & $97.1-99.4$ \\
\hline SDMS & $87.0-100.0$ & $86.1-100.0$ & $87.8-100.0$ & $86.8-100.0$ & 96.8-100.0 & 92.9-100.0 & 98.4-100.0 & 97.9-100.0 \\
\hline SDHS & $87.0-100.0$ & $86.1-100.0$ & $87.8-100.0$ & $86.8-100.0$ & $96.8-100.0$ & $92.9-100.0$ & 98.4-100.0 & 97.9-100.0 \\
\hline SDLC & $86.5-100.0$ & 85.4-99.8 & 87.3-99.6 & $86.2-99.9$ & $96.8-100.0$ & 92.0-99.7 & $97.6-99.2$ & $98.0-100.0$ \\
\hline AHQY & $86.5-100.0$ & $85.2-99.8$ & 87.5-99.6 & $86.2-99.9$ & 96.8-100.0 & $91.8-99.7$ & $98.2-99.5$ & 97.9-99.9 \\
\hline SDDZ & $86.8-100.0$ & $86.2-100.0$ & 87.7-100 & $86.5-100.0$ & 96.6-100.0 & 93.5-100.0 & 98.4-100.0 & 97.9-100.0 \\
\hline NMCF & $86.8-100.0$ & $86.2-100.0$ & $87.7-100$ & $86.5-100.0$ & $96.6-100.0$ & 93.5-100.0 & 98.4-100.0 & 97.9-100.0 \\
\hline Mean value & 86.7-99.9 & 85.8-99.8 & 87.6-99.9 & $86.5-99.9$ & $96.5-99.9$ & $92.5-99.68$ & $98.2-99.8$ & $97.8-99.9$ \\
\hline
\end{tabular}




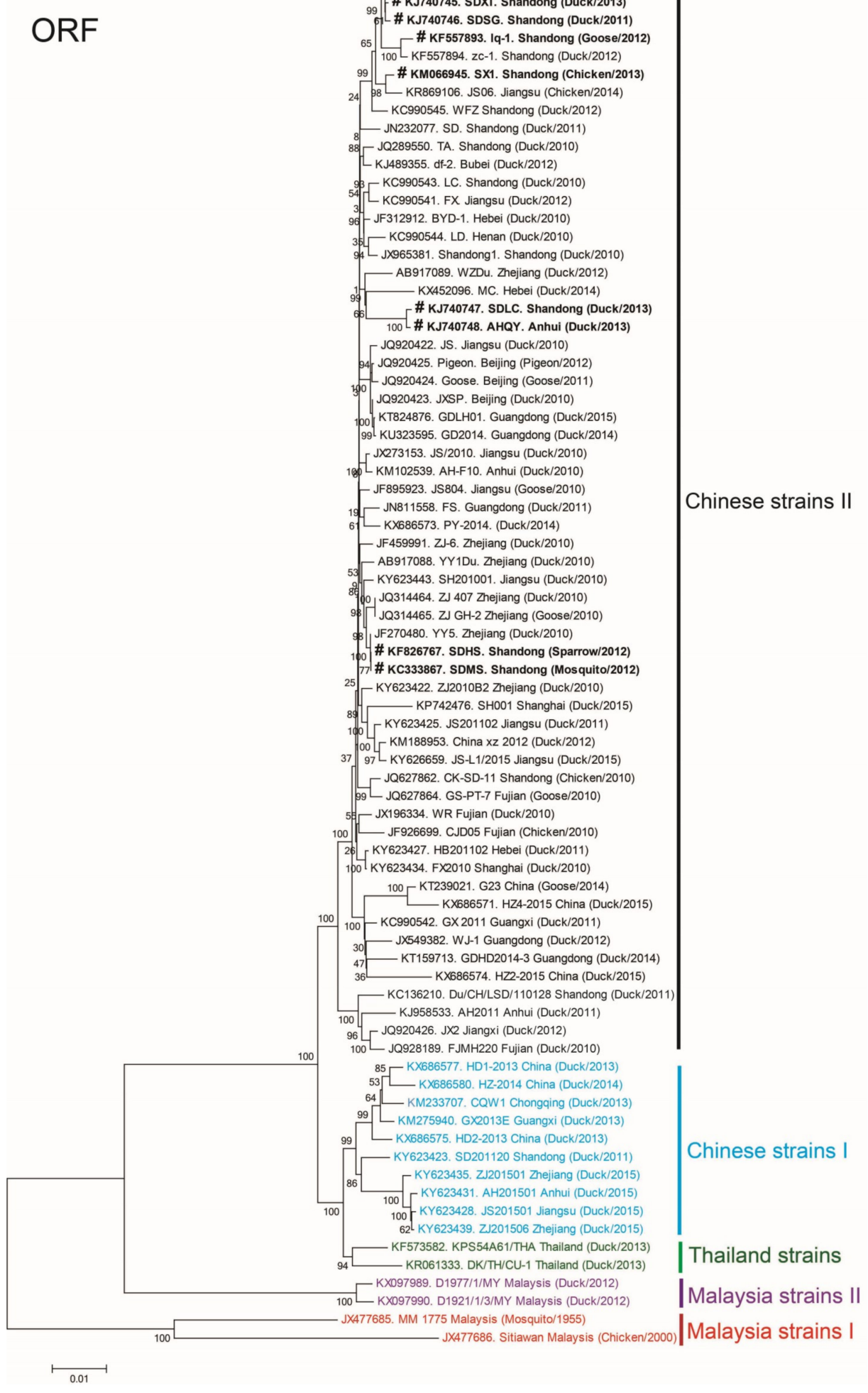

Figure 2. Phylogenetic analysis of the open-reading frame sequences of 78 representative Tembusu virus strains. The phylogenetic trees were constructed using MEGA 7.0 software. Bootstrap consensus values based on 1000 replicates are indicated at each branch point as a percentage. The sequences from the 11 virus strains isolated by in this study are presented in bold. The scale bar indicates the number of nucleotide substitutions per site. 


\subsection{Viral Protein Structure and Glycosylation Site}

The tertiary structures of E, NS1, NS3, and NS5 of the 11 TMUV isolates were modeled using Swiss Model. Mutations were only found in NS1 of KF557893 (1q-1/goose/shandong/2012), KJ740747 (SDLC/duck/shandong/2013), KJ740748 (AHQY/duck/Anhui/2013), and KM066945 (SX1/chicken/shandong/2013), as these strains had a ${ }^{180} \mathrm{TAV}^{182}$ mutation that changed a random crimp into an alpha helix (Figure 3). However, compared with the conserved sequence, the NS1 amino acid sequences of the mutant strains were unchanged (i.e., TAV vs. TAV).
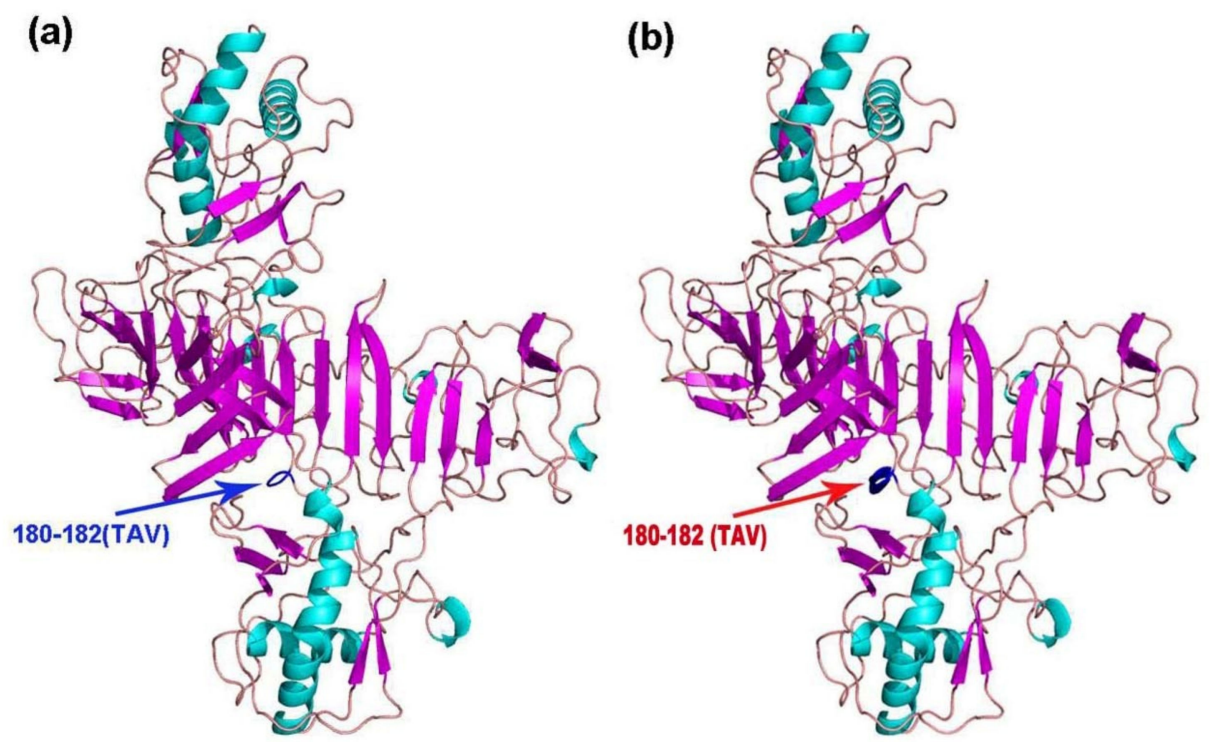

Figure 3. Cartoon scheme view of the NS1 protein structure. (a) Conserved structure of NS1 protein; (b) mutant NS1 protein structure of KF557893 (1q-1/goose/shandong/2012), KJ740747 (SDLC/duck/shandong/2013), KJ740748 (AHQY/duck/Anhui/2013), and KM066945 (SX1/chicken/shandong/2013).

A mutated glycosylation site was also found in NS1, and the mutant strains included KF557893 (1q-1/goose/shandong/2012), KJ740745 (SDXT/duck/shandong/2013), KJ740746 (SDSG/duck/shandong/2011), SDDZ/duck/shandong/2016, NMCF/duck/inner mongolia/2017, and TC2B/duck/shandong/2011. Compared with other representative TMUV strains, these strains had a glycosylation site mutation at amino acid site 175 from NTTD to NITD (Figure 4).
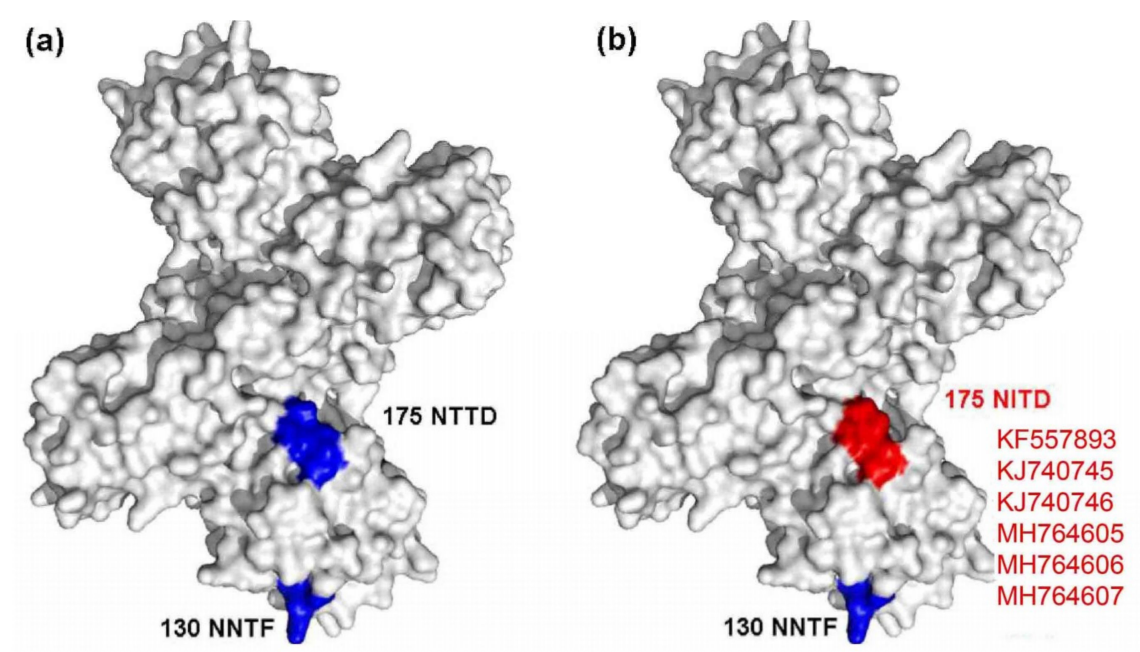

Figure 4. Diagram of NS1 glycosylation sites. (a) Conserved glycosylation sites are marked in blue; (b) the mutated glycosylation site is marked in red. 


\section{Discussion}

DTMUV is a major pathogen that endangers waterfowl, and has caused several billion dollars of losses in the Chinese poultry industry since 2010 [16]. Increasing our knowledge of the genetic evolution of DTMUV is important for realizing the virus protein mutations, and gaining an insight into the protein structure can also provide strategies for vaccine development, which further lay a foundation for controlling the prevalence of DTMUV infection. To date, several TMUV strains have been isolated in China, and their genomic sequences have been uploaded to GenBank; however, few studies have explored the genetic evolution characteristics of these strains' genomic sequences. No epidemiological surveys of TMUVs have been conducted in China. Thus, based on our previous work (i.e., 11 TMUV strains isolated by our team), the phylogenetic, protein tertiary structure, and glycosylation site analyses were employed to explore the genetic divergence of TMUV in Northern China.

In the present study, according to the phylogenetic trees of ORF, E, NS1, NS3, and NS5 gene sequences of 78 TMUV representative strains, we can see that current Chinese TMUV strains are mainly divided into two distinct genotypes (termed as Chinese strains I and Chinese strains II), and the 11 isolates are mainly clustered into Chinese strains II, which is also named DTMUV II as the dominant strain [5]. Notably, the nucleotide and amino acid homologies of NS1 were lower than those of $E$, NS3, and NS5 (i.e., (85.8-99.8\% and $92.5-99.68 \%)$ vs. (86.7-99.9\% and $96.5-99.9 \%),(87.6-99.9 \%$ and $98.2-99.8 \%)$, and $(86.5-99.9 \%$ and $97.8-99.9 \%)$ respectively), which indicates that NS1 is more variable than the other three proteins.

In the present study, to visually reflect the mutations of the 11 isolates, the tertiary structure predictions of E, NS1, NS3, and NS5 proteins were conducted using Swiss Model. Interestingly, only the NS1 protein (of 4 of 11 strains) had a ${ }^{180} \mathrm{TAV}^{182}$ mutation that changed the tertiary structure. Likewise, the N-linked glycosylation site mutation (6 of 11 strains) was also found in the NS1 protein. It is unclear why these mutations occurred only in the NS1 protein. One reason could be the occurrence of "immune selection pressure" [17], which can cause mutations in the structure of a virus' antigenic proteins in an effort to evade the host immune response. As reported previously, Flavivirus NS1 protein is a vital antigenic protein that contains multiple $\mathrm{T}$ cell and $\mathrm{B}$ cell epitopes that can induce the production of non-neutralizing protective antibodies [18-20], and also plays a significant role in immune evasion [21-23]. Therefore, these findings indicate that the NS1 protein may be a hypervariable region for genetic evolution.

Furthermore, our epidemiological data revealed that TMUV has been circulating in 17 provinces of China, compared to 9-10 provinces in 2011 [12,24]. This may be because of the expansion of the duck breeding industry and increased transportation capacity of China in recent years, which could accelerate the spread of the virus. Notably, the number of virus host species has increased from four in 2011 (ducks, chickens, geese, and mosquitoes) to six at present (ducks, chickens, geese, sparrows, pigeons, and mosquitoes), which suggests we need to expand the detection range in clinical practice in future. Additionally, reports have indicated that the virus can also infect mice and humans [13-15]. These findings imply that the virus has expanded its host range and that it may pose a threat to mammals' health. Furthermore, the higher incidence in autumn may be associated with the transmission of the virus by mosquitoes [10], the population sizes of which peak in autumn in Northern China.

\section{Conclusions}

In summary, 11 TMUV isolates were obtained from six hosts in Northern China, and all 11 isolates belonged to the dominant cluster in China. The territorial scope of TMUV has expanded in China, and multivalent vaccines are needed to control its spread. Furthermore, our findings indicated that the NS1 protein might be a hypervariable region for genetic evolution. These findings should contribute to the development of strategies for controlling TMUV spread. 
Supplementary Materials: The following are available online at http:/ / www.mdpi.com/1999-4915/10/9/485/s1, Figure S1: Phylogenetic analysis of E gene sequences of 78 representative Tembusu virus strains. Figure S2: Phylogenetic analysis of NS1 gene sequences of 78 representative Tembusu virus strains. Figure S3: Phylogenetic analysis of NS3 gene sequences of 78 representative Tembusu virus strains. Figure S4: Phylogenetic analysis of NS5 gene sequences of 78 representative Tembusu virus strains. Table S1: Description of 78 TMUV representative isolates used in this study. Table S2: Primers used in the study.

Author Contributions: G.Y. completed most of the experiments with the help of Y.L.; Y.T. and Y.D. provide the materials, designed experiments and reviewed the manuscript. All authors have read and approved the manuscript for publication.

Acknowledgments: This research was funded by the National Natural Science Foundation of China (31602047); the National Natural Science Foundation of China (31472199); the National Key Research and Development Program of China (2016YFD0500107); the China Agriculture Research System (CARS-42-19); Science and Technology Development Plan of Shandong Province (2014GNC111023); Funds of Shandong "Double Tops" Program.

Conflicts of Interest: The authors have no conflicts of interest to declare.

\section{References}

1. Yu, G.; Lin, Y.; Tang, Y.; Diao, Y. Comparative Transcriptomic Analysis of Immune-Related Gene Expression in Duck Embryo Fibroblasts Following Duck Tembusu Virus Infection. Int. J. Mol. Sci. 2018, 19, 2328. [CrossRef] [PubMed]

2. Lei, W.; Guo, X.; Fu, S.; Feng, Y.; Tao, X.; Gao, X.; Song, J.; Yang, Z.; Zhou, H.; Liang, G. The genetic characteristics and evolution of Tembusu virus. Vet. Microbiol. 2017, 201, 32-41. [CrossRef] [PubMed]

3. Homonnay, Z.G.; Kovacs, E.W.; Banyai, K.; Albert, M.; Feher, E.; Mato, T.; Tatar-Kis, T.; Palya, V. Tembusu-like flavivirus (Perak virus) as the cause of neurological disease outbreaks in young Pekin ducks. Avian Pathol. 2014, 43, 552-560. [CrossRef] [PubMed]

4. Kono, Y.; Tsukamoto, K.; Hamid, M.; Darus, A.; Lian, T.; Sam, L.; Yok, C.; Di, K.; Lim, K.; Yamaguchi, S.; et al. Encephalitis and retarded growth of chicks caused by Sitiawan virus, a new isolate belonging to the genus Flavivirus.pdf. Am. J. Trop. Med. Hyg. 2000, 63, 94-101. [CrossRef] [PubMed]

5. Yu, K.; Sheng, Z.Z.; Huang, B.; Ma, X.; Li, Y.; Yuan, X.; Qin, Z.; Wang, D.; Chakravarty, S.; Li, F.; et al. Structural, antigenic, and evolutionary characterizations of the envelope protein of newly emerging Duck Tembusu Virus. PLoS ONE 2013, 8, e71319. [CrossRef] [PubMed]

6. Huang, X.; Han, K.; Zhao, D.; Liu, Y.; Zhang, J.; Niu, H.; Zhang, K.; Zhu, J.; Wu, D.; Gao, L.; et al. Identification and molecular characterization of a novel flavivirus isolated from geese in China. Res. Vet. Sci. 2013, 94, 774-780. [CrossRef] [PubMed]

7. Ti, J.; Zhang, L.; Li, Z.; Zhao, D.; Zhang, Y.; Li, F.; Diao, Y. Effect of age and inoculation route on the infection of duck Tembusu virus in Goslings. Vet. Microbiol. 2015, 181, 190-197. [CrossRef] [PubMed]

8. He, Y.; Wang, A.; Chen, S.; Wu, Z.; Zhang, J.; Wang, M.; Jia, R.; Zhu, D.; Liu, M.; Yang, Q.; et al. Differential immune-related gene expression in the spleens of duck Tembusu virus-infected goslings. Vet. Microbiol. 2017, 212, 39-47. [CrossRef] [PubMed]

9. Fu, G.; Chen, C.; Huang, Y.; Cheng, L.; Fu, Q.; Wan, C.; Shi, S.; Chen, H.; Liu, W. Comparative analysis of transcriptional profiles of retinoic-acid-induced gene I-like receptors and interferons in seven tissues from ducks infected with avian Tembusu virus. Arch. Virol. 2016, 161, 11-18. [CrossRef] [PubMed]

10. Tang, Y.; Diao, Y.; Chen, H.; Ou, Q.; Liu, X.; Gao, X.; Yu, C.; Wang, L. Isolation and genetic characterization of a tembusu virus strain isolated from mosquitoes in Shandong, China. Transbound. Emerg. Dis. 2015, 62, 209-216. [CrossRef] [PubMed]

11. Tang, Y.; Diao, Y.; Yu, C.; Gao, X.; Ju, X.; Xue, C.; Liu, X.; Ge, P.; Qu, J.; Zhang, D. Characterization of a Tembusu virus isolated from naturally infected house sparrows (Passer domesticus) in Northern China. Transbound. Emerg. Dis. 2013, 60, 152-158. [CrossRef] [PubMed]

12. Liu, P.; Lu, H.; Li, S.; Moureau, G.; Deng, Y.Q.; Wang, Y.; Zhang, L.; Jiang, T.; de Lamballerie, X.; Qin, C.F.; et al. Genomic and antigenic characterization of the newly emerging Chinese duck egg-drop syndrome flavivirus: Genomic comparison with Tembusu and Sitiawan viruses. J. Gen. Virol. 2012, 93, 2158-2170. [CrossRef] [PubMed]

13. Li, S.; Li, X.; Zhang, L.; Wang, Y.; Yu, X.; Tian, K.; Su, W.; Han, B.; Su, J. Duck Tembusu virus exhibits neurovirulence in BALB_c mice. Virol. J. 2013, 10, 260. [CrossRef] [PubMed] 
14. Ti, J.; Zhang, M.; Li, Z.; Li, X.; Diao, Y. Duck Tembusu Virus Exhibits Pathogenicity to Kunming Mice by Intracerebral Inoculation. Front. Microbiol. 2016, 7, 190. [CrossRef] [PubMed]

15. Tang, Y.; Gao, X.; Diao, Y.; Feng, Q.; Chen, H.; Liu, X.; Ge, P.; Yu, C. Tembusu virus in human, China. Transbound. Emerg. Dis. 2013, 60, 193-196. [CrossRef] [PubMed]

16. Yu, G.; Yu, X.; Yang, G.; Tang, Y.; Diao, Y. A novel diagnostic method to detect Duck Tembusu Virus: A colloidal gold-based immunochromatographic assay. Front. Microbiol. 2018, 9, 1001. [CrossRef] [PubMed]

17. Cui, Z. Multiplicity of viral quasispecies and its evolution under selective pressure of antibody immunity. Chin. Sci. Bull. 2013, 25, 843-852.

18. Schlesinger, J.J. Flavivirus nonstructural protein NS1: complementary surprises. Proc. Natl. Acad. Sci. USA 2006, 103, 18879-18880. [CrossRef] [PubMed]

19. Tafuku, S.; Miyata, T.; Tadano, M.; Mitsumata, R.; Kawakami, H.; Harakuni, T.; Sewaki, T.; Arakawa, T. Japanese encephalitis virus structural and nonstructural proteins expressed in Escherichia coli induce protective immunity in mice. Microbes Infect. 2012, 14, 169-176. [CrossRef] [PubMed]

20. Bralut, A.; Domi, A.; McDonald, E.M.; Talmi-Frank, D.; McCurley, N.; Basu, R.; Robinson, H.L.; Hellerstein, M.; Duggal, N.K.; Bowen, R.A.; et al. A Zika vaccine targeting NS1 protein protects immunocompetent adult mice in a lethal challenge model. Sci. Rep. 2017, 7, 14769. [CrossRef] [PubMed]

21. Muller, D.A.; Young, P.R. The flavivirus NS1 protein: Molecular and structural biology, immunology, role in pathogenesis and application as a diagnostic biomarker. Antivir. Res. 2013, 98, 192-208. [CrossRef] [PubMed]

22. Akey, D.L.; Brown, W.C.; Dutta, S.; Konwerski, J.; Jose, J.; Jurkiw, T.J.; DelProposto, J.; Ogata, C.M.; Skiniotis, G.; Kuhn, R.J.; et al. Flavivirus NS1 structures reveal surfaces for associations with membranes and the immune system. Science 2014, 343, 881-885. [CrossRef] [PubMed]

23. Wang, J.; Lei, C.Q.; Ji, Y.; Zhou, H.; Ren, Y.; Peng, Q.; Zeng, Y.; Jia, Y.; Ge, J.; Zhong, B.; et al. Duck Tembusu Virus nonstructural protein 1 antagonizes IFN- $\beta$ signaling pathways by targeting VISA. J. Immunol. 2016, 197, 4704-4713. [CrossRef] [PubMed]

24. Su, J.; Li, S.; Hu, X.; Yu, X.; Wang, Y.; Liu, P.; Lu, X.; Zhang, G.; Hu, X.; Liu, D.; et al. Duck egg-drop syndrome caused by BYD virus, a new Tembusu-related flavivirus. PLoS ONE 2011, 6, e18106. [CrossRef] [PubMed]

(C) 2018 by the authors. Licensee MDPI, Basel, Switzerland. This article is an open access article distributed under the terms and conditions of the Creative Commons Attribution (CC BY) license (http:/ / creativecommons.org/licenses/by/4.0/). 